\title{
OVERCOMING SOCIAL INCLUSION BARRIERS FOR PEOPLE WITH INTELLECTUAL DISABILITY
}

\author{
Simone Zorzi \\ Ecoinstituto Friuli Venezia Giulia, Italy \\ Gunars Strods \\ Rezekne Academy of Technologies, Latvia
}

\begin{abstract}
The cultural changes that have taken place and the social sciences contributions that have been published over the last few decades have inaugurated a new vision of people with disabilities that upholds the values of rights, equality, participation, and social inclusion.

Although these changes have been widely supported through the ratification of important international treaties (for example, the United Nations Convention on the Rights of Persons with Disabilities) and by scientific evidence, however, they are still struggling to penetrate into the wider social and cultural system, or to become common practice in services directed at people with disabilities. Social inclusion for people with disabilities, and in particular intellectual disabilities, remains, in fact, a difficult objective to achieve. Above all, cultural barriers are still a hindering factor in social inclusion processes. This paper is a commentary on the research carried out within the two-year European project ESEC (Extending Social Educators Competences).
\end{abstract}

Keywords: deinstitutionalization, quality of life, intellectual disability, social inclusion, stereotypes.

\section{Introduction}

Usually, reflections on disability have been limited to specific areas, such as health, social care, or education. The premise underlying this "confinement" was the widespread and deep-rooted belief that disability is necessarily an individual problem. Accordingly, it is considered a deficit condition that deprives the person of the possibility of living meaningful experiences and which, therefore, cannot in any way be chosen or preferred to able-bodied life, as it has a decisive influence on the possibility of living in a dignified way. Since the sixties, however, this dogmatic outlook has gradually begun to crumble, especially following the lively and fierce criticism directed - at the political level, by the disability rights movement, and at the academic level, by the so-called disability studies.

As a result of this activism and following numerous contributions in the field of social-health science, the last few decades have seen a progressive shift, firstly from an individualistic to a "social conception", and then on to a "bio-psycho-social conception” of disability (World Health Organization, 2007). 
This has reimagined the issue of disability, transforming it into an articulated and multidimensional phenomenon. Due to this approach, disability has been reconfigured as being the product of a complex interaction between the subject and the surrounding environment. In this way, disability has become a theme that has transcended the medical-welfare field and ended up influencing the social, cultural, and policy spheres. Disability is actually no longer considered in terms of individual deficit. On the contrary, the approach to disability is based on positive models that emphasize the potential, the empowerment, and the individual rights of people with disabilities that must be supported and guaranteed for their Quality of life [QoL]. QoL has, over the last two decades, undoubtedly become the scientifically validated framework on which to program and implement policies, services, and practices for people with intellectual disability (Renwick \& Brown, 1996; Buntnix \& Schalock, 2010). One of most important constructs that is closely tied to QoL is Social Inclusion. It is considered a core domain of QoL, and is seen as being essential for human functioning (Verdonschot, deWitte, Reichrath, Buntinx, \& Curfs, 2009). There has broadly been agreement across various quantitative and qualitative studies that a move from any type of institutional setting to community living is associated with a QoL improvement. The Convention on the Rights of Persons with Disabilities (United Nations, 2006) reinforces social inclusion and independent living as being a fundamental right for persons with disabilities. Despite the recognition of these rights, however, the opportunity to be part of the community remain limited for people with intellectual disability, and they participate far less in recreational and community-programs/activities than people without intellectual disability (Dusseljee, Rijken, Cardol, Curfs, \& Groenewegen, 2011). Most of those with intellectual disability still live in institutions, and there is a general lack of opportunities for them to be involved in the typical relationships and normal activities of community life. They face many challenges with regard to education and employment, health services and social support, transport, and access to buildings. They also face challenges concerning housing, leisure, and their overall social and political life. All this has a profound effect on their QoL and on their possibilities of developing positive existential trajectories.

\section{Research objectives and methodology}

This paper is a commentary that presents some reflections coming from the two-year project ESEC (Extending Social Educators Competences) supported by the European Union. The ESEC project began in December 2018 and will end in November 2020. It involves partners from five European countries (Italy, Latvia, Greece, Spain, and Poland), and pursues the general objective of extending the current competence of social educators. More precisely, it focuses on social 
inclusion and will design and experiment an innovative parent-training program for parents of children with special needs.

The research was based on a two-stage procedure. We first searched on online databases (Scopus, TR Web of Sciences, SAGE, Wiley Online Library, IEEE Xplore Digital Library, and Google Scholar), selecting a pool of candidate articles, projects, and initiatives relevant to the project aim.

In the following paragraphs some considerations on social inclusion are presented focusing on current issues on social inclusion and intellectual disabilities.

\section{Defining Social inclusion}

Social inclusion is a broad construct linked to numerous economic, social, political, and cultural aspects, which is used in various fields and disciplines. In a very general sense, inclusion means being involved in a form of social life (Ikäheimo, 2009). The term 'social life' refers to abstract notions such as inclusion in typical activities of human interaction and economic and political life as well as to involvement in close relationships, such as with friends and family. Important aspects of social inclusion include having a valued role and participation in society, developing relationships, and having a sense of belonging (Lemay, 2006). Social inclusion does not concern only the characteristics of people or contexts, but the processes of interaction between them which allow people, with disabilities or other differences, to feel recognized and valued, just like any other member of the community to which they belong. Cobigo, OuelletteKuntz, Lysaght \& Martin (2012) defined social inclusion as representing a series of complex interactions between environmental factors and personal characteristics.

Understanding the processes of inclusion requires the application of ecological approaches that integrate different factors in the different layers of the social system: the individual level, interpersonal level, organizational level, community level, and socio-political level (Verdonschot et al., 2009). These variables exist in a mutual relationship and can create the conditions enabling or disabling social inclusion outcomes.

\section{Social Inclusion value}

Inclusion contributes to assure equality of opportunity, full participation, independent living, and economic self-sufficiency for individuals. For social inclusion to be achieved, it requires development, freedom, and recognition (Felder, 2018). The relationship between recognition and inclusion is of anthropological significance: human individuals structurally rely on others to 
Zorzi \& Strods, 2020. Overcoming Social Inclusion Barriers for People with Intellectual Disability

develop all, or at least some, of their cognitive, moral, and affective capacities. Recognition as a human being with certain basic needs (love and care, for instance) is indispensable for a healthy development.

The relationship between freedom and social inclusion is not immediate to understand. If we consider that people with intellectual disability often come from inclusions or exclusions imposed by others, then the relationship between inclusion and freedom becomes more apparent. In the case of disability, often a lack of inclusion and opportunities for making choices may derive from over protection attitudes. In this regard, Perske (1972) introduced the concept of dignity of risk. Dignity of risk is the notion that self-determination and the right to take reasonable risks are essential prerequisites for dignity and self-esteem. Because of this, the ability to take risks should not be impeded by excessively cautious caregivers. On the contrary, overprotection of people with disabilities creates a sense of low self-esteem and underachievement due to the lowered expectations that come with overprotection. The internalization of low expectations also causes the person with a disability to believe that they are less capable than others in similar situations.

\section{Cultural barriers to social inclusion}

Obviously, individual factors constitute one of the basic factors of the difficulties in inclusion processes that people with intellectual disabilities usually face. Individual enabling/disabling conditions may include a person's level of functioning, self-motivation, confidence, their knowledge of the area and of the activities on offer, and the use of goal setting. Several studies have shown an increase in the probability of negative inclusion outcomes in the presence of higher levels of impairment (Bowe, 2003; Caton \& Kagan, 2007). At the same time, literature highlights that contextual and social factors influence social inclusion processes in the same way (Burchardt, 2004). For people with intellectual disabilities, in fact, social inclusion outcomes depend particularly on policies, attitudes, and available opportunities provided by social contexts (Duvdevany \& Arar, 2004). In addition to the individual dimensions, the contextual components have a decisive impact on the social inclusion and individual personal development outcomes (Committee on Disability in America, 2007). Among the contextual factors, social expectations for those with disabilities play a crucial role. 


\section{Social expectations and stereotypes of people with intellectual disabilities}

According to Goffman, "Society establishes the means of categorizing persons and the complement of attributes felt to be ordinary and natural for members of these categories." (Goffman, 1963, p. 5). Even today, expectations seem to be strongly influenced by stigma and stereotypes of disability that are still very much present at a social level. These stereotypes negatively affect the policies and planning of services and interventions for people with disabilities. Moreover, they contribute to slowing down the paradigm shift necessary for the full promotion of the rights of participation and social inclusion anticipated by the UN Convention.

Certain stereotypes used to label those with disabilities still persist at different levels of the social system. Incomplete information, mistaken perceptions, isolation, and segregation have perpetrated many of these stereotypes. The way people think about disability affects the care and education of these persons. Myths and misconceptions about disability are common. Promoting negative images of disability represents a form of discrimination because it creates barriers to full citizenship (Pelleboer-Gunnink \& Van Weeghel, Embregts, 2019). Stereotypes of people with disabilities portray them in a range of ways, from being pitiable and pathetic, sinister or evil, tragic but brave, laughable, aggressive, burdens/outcasts, and asexual, and of being incapable of fully participating in everyday life. There is a habit to consider a person with an intellectual disability as a "childlike" and thus deny them the recognition of their real age and existential phase (Shakespeare, 2013). This produces a thought of people with disabilities as "incompetent and dependent" that do not possess the intellectual resources and learning potential required to address the social demands to which we, as members of the community, are typically subject. All these attitudes are deeply rooted in a sort of "autopilot driver" through which the existential designs of people with disabilities are largely conceived.

The literature in recent years has underlined that the attitudes of professional carers towards young people with different types of disabilities has a profound influence on many aspects of their social inclusion, their treatment, and the outcomes that are achieved in the future in their favor (Colella, DeNisi, \& Varma, 1998; Annable et al., 2003).

Expectations and attitudes constitute a significant predictor compared to the possibilities of young people with intellectual disability entering the world of work (Holwerda, Brouwer, de Boer, Groothoff, \& Van der Klink, 2015).

These data indicate the change has not yet been fully realized, and that the risk of falling into the old ways of thinking is very high. 
Zorzi \& Strods, 2020. Overcoming Social Inclusion Barriers for People with Intellectual Disability

\section{Difficult to change paradigms}

What is meant by paradigmatic change? What is the level of change when it involves not simply a few aspects, but an entire paradigm? For Thomas Kuhn, the term "paradigm" indicates a coherent set of principles that underlie universally recognized scientific achievements, which, for a certain period of time, provide a model of acceptable problems and solutions to those who practice within a particular field of research. In other words, the paradigm is a profound structure, made up of beliefs and assumptions, long before the establishment of scientific models of explanation (McNamara, 1979). Thus, a paradigm is constructed and reinforced on the basis of non-scientific factors, such as the social values and psychological conditions of a historical period, and the view of the world shared at the time. As time passes, however, scientific and cultural progress forces new problems to be confronted that it will not be able to solve. The inability to resolve these new issues cause a crisis. In this way, the scientific and cultural community begins to question the validity of the paradigm that had been accepted until that moment. In these circumstances, "extraordinary science", that is, scientific activity aimed at finding new foundations of thought capable of solving the crisis, can find space. Once such a new set of values, prospects, and inspirational criteria find consensus in the community, a so-called "Scientific revolution" occurs, understood as an episode of development in which an old paradigm is replaced, in whole or in part, by a new and incompatible one. The change of a paradigm, however, is not a linear and simple process, due to the fact that those who are called on to develop the new paradigm have, in reality, always lived immersed in the old one that they must now falsify in order to move forward. Furthermore, the design of, and then the adherence to, a new paradigm does not depend primarily on the perception of past errors, but on how much the new intuition and, above all, the future prospect is worth pursuing.

\section{Key steps for the promotion of social inclusion}

So then, what are the future prospects for people with disabilities that should be stimulated in order to promote the rights of equality, participation, and social inclusion? How can we speed up the change process? First of all, the scientific and educational community should strive to break down the wall of prejudice and change the traditional way of approaching people with disabilities in order to enhance, in their favor, the opportunities for them to be recognized as "helpful persons". Giangreco (2017) highlights the fundamental need to guarantee to people with disabilities their simultaneous access to inclusive environments and necessary connected supports. In order to promote and archive social inclusion outcomes some educational key steps are indicated: 
- "See the Person, Not Just the Disability": the needs for social inclusion are the same for people with and without disability. Educators must work to change the social imagine of people with intellectual disability.

- Work to support full community access of a person with disability: a person with intellectual disability should have access to the full range of environments and experiences available to other individuals of their same age.

- Individualize learning outcomes: overcome the standardized approach towards outcomes centered on the person's subjectivity.

- Use Age-Appropriate Approaches in contrast to the eternal child stereotypes.

- Encourage enabling approaches to promote the maximum level of skills and competences that the person can reach.

- Use of natural support to foster as much as possible the opportunities for building relationships and participating in the community in the same way as any other individuals of the same age.

\section{Conclusion}

From our research emerges that, although social inclusion is an essential outcome for the life of people with intellectual disabilities, many cultural barriers still exist.

We found that social stereotypes towards people with intellectual disabilities negatively affect educational interventions and services. They slow down the process of change in respect to the promotion of rights and the development of positive existential trajectories. Because of the persistence of these social visions, people with intellectual disabilities continue to live in contexts of segregation far removed from participation in social and community life.

Accordingly, our opinion is that educational interventions should be applied not only in respect to the person, but also to the social and cultural contexts. It is essential to work on the social context in order to provide real opportunities for people to access and participate in community life.

In this perspective, the full application of the rights of people with disabilities individuated by the United Nations Convention and the application of the evidence based models and interventions indicated by the social sciences requires a culture and paradigm change. In the absence of such a paradigm shift, a true evolution cannot be achieved, and the risk of regressing backwards to the vision and the stigma of the past continue to be very high. There is, then, still a long way to go, and the contribution of scientific research will be fundamental. Many steps have already been taken, however, and the route for change has been defined. 
Zorzi \& Strods, 2020. Overcoming Social Inclusion Barriers for People with Intellectual Disability

This challenge constitutes a real opportunity, not only to change the future and the QoL of people with disabilities, but also to launch a renewed ethical and professional perspective for practitioners and service providers.

\section{References}

Annable, G., Watters, C., Stienstra, D., Symanzik, A., Tully, B.L., \& Stuewer, N. (2003). Students with disabilities: Transition from post-secondary education to work. Phase I report, Winnipeg, Canadian Centre of Disability Studies.

Bowe, F.G. (2003). Transition for deaf and hard-of-hearing students: A blueprint for change, Journal of Deaf Studies and Deaf Education, 8(4), 485-493.

Buntinx, W.H.E., \& Schalock, RL. (2010). Models of Disability, Quality of Life, and Individualized Supports: Implications for professional practice in Intellectual Disability. Journal of Policy and Practice in Intellectual Disabilities, 7(4), 283-294.

Burchardt, T. (2004). Aiming high: The educational and occupational aspirations and of young disabled people, Support for Learning, 19(4), 181-186.

Caton, S., \& Kagan, C. (2007). Comparing transition expectations of young people with moderate learning disabilities with other vulnerable youth and with their non-disabled counterparts, Disability and Society, 22(5), 473-88.

Cobigo, V., Ouellette-Kuntz, H., Lysaght, R., \& Martin, L. (2012). Shifting our Conceptualization of Social Inclusion. Stigma Research and Action Journal, 2(2), 75-84.

Colella, A., DeNisi, A.S., \& Varma, A. (1998). The impact of ratee's disability on performance judgments and choice as partner: the role of disability-job fit stereotypes and interdependence of rewards, Journal of Applied Psychology, 83(1), 102-111.

Committee on Disability in America (2007). Health care transitions for young people. In Field, M.J., \& Jette, A.M. (Eds.), Future of disability in America, (pp. 98-135), Washington DC, The National Academies Press.

Dusseljee, J.C.E., Rijken, P.M., Cardol, M., Curfs, L.M.G., \& Groenewegen, P.P. (2011). Participation in daytime activities among people with mild or moderate intellectual disability. Journal of Intellectual Disability Research, 55(1), 4-18.

Duvdevany, L., \& Arar, E. (2004). Leisure activities, friendships, and quality of life of persons with intellectual disability: foster homes versus community residential settings. International Journal of Rehabilitation Research, 27(4), 289-296.

Felder, F. (2018). The Value of Inclusion. Journal of Philosophy of Education, 52(1).

Giangreco, M.F. (2017). Expanding Opportunities for Students with Intellectual Disability. Educational Leadership, 74(7), 52-57.

Goffman, E. (1963). Stigma: Notes on the management of spoiled identity. Englewood Cliffs, NJ: Prentice-Hall.

Holwerda, A., Brouwer, S., de Boer, M.R., Groothoff, J.W., \& Van der Klink, J.J (2015). Expectations from different perspectives on future work outcome of young adults with intellectual and developmental disabilities, Journal of Occupational Rehabilitation, 25(1), 96-104.

Ikäheimo, H. (2009). A vital human need: Recognition as inclusion in personhood. European Journal of Political Theory, 8(1), 31-45.

Lemay, R. (2006). Social role valorization insights into the social integration conundrum. Mental Retardation, 44(1), 1-12. 
McNamara, D.R. (1979). Paradigm lost: Thomas Kuhn and educational research. British educational research journal, 5(2).

Perske, R. (1972). The dignity of risk and the mentally retarded. National Association for Retarded Citizens.

Pelleboer-Gunnink, H.A., van Weeghel, J., \& Embregts, P.J. (2019). Public stigmatisation of people with intellectual disabilities: a mixed-method population survey into stereotypes and their relationship with familiarity and discrimination. Disability and rehabilitation, 26, 1-9.

Renwick, R., \& Brown, I. (1996). Being, belonging, becoming: the centre for health promotion model of quality of life. In R. Renwick, I. Brown, \& M. Nagler (Eds.), Quality of life in health promotion and rehabilitation: conceptual approaches, issues, and applications. Thousand Oaks, CA: Sage.

Shakespeare, T. (2013). Facing up to disability. Community Eye Health, 26(81), 1-3.

United Nations. (2006). Convention on the rights of persons with disabilities, New York, United Nations.

Verdonschot, M.M.L., de Witte, L.P., Reichrath, E., Buntinx, W.H.E., \& Curfs, L.M.G. (2009). Community participation of people with an intellectual disability: A review of empirical findings. Journal of Intellectual Disability Research, 53, 303-318.

World Health Organization. (2007). International Classification of Functioning, Disability, and Health: Children \& Youth Version: ICF-CY. World Health Organization. 

SOCIĀLĀ PEDAGOĢIJA

Social Pedagogy 
